\title{
0 intelectual e seu outro: Foucault e Sartre
}

\author{
RENATO JANINE RIBEIRO
}

RESUMO: Foucault pensou o papel do intelectual na contestação a Sartre e aos pressupostos do engagement, em especial os associados à filosofia da consciência e ao humanismo. Depois de 1968, porém, quando os fundamentos políticos do sartrismo desabavam - em particular a proximidade do Partido Comunista - Sartre pôde fazer causa comum com Foucault, ao mesmo tempo que este assumia, de boa ou má vontade, papéis que sempre negara, como o da voz pública.

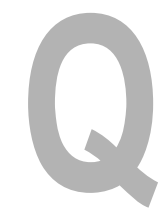

ue papel Michel Foucault alocou ao intelectual? Eis uma questão que é essencial formular aqui, não só por sermos, nós, desta profissão, e assim lidarmos com um tema que fala a nosso narcisismo; mas, sobretudo, porque junto com o anti-humanismo, a derrubada da primazia que a filosofia existencialista outorgara ao homem, Foucault também efetuou uma liquidação em regra desse outro legado sartriano que foi o relevo conferido ao intelectual enquanto consciência moral da política. Uma política humanista tinha, assim, uma espécie de fiador no intelectual; mas, para explicitar isso, devemos passar por Sartre, que nas questões precisas da militância política (devemos quase nos controlar para não falar em "engajamento") e do papel do intelectual, é a referência contra a qual Foucault se constitui ${ }^{1}$.

Seria impossível entender a política sartriana sem a presença, ainda que distante, do comunismo. É verdade que ofilósofo jamais se filiou ao Partido, e que suas relações foram, por vezes, muito tensas. Depois da repressão soviética à rebelião húngara, ele escreve um longo ensaio, $O$ fantasma de Stalin (Sartre, s/d), que constitui um acerto de contas com o que é

Versão inicial e parcial deste artigo foi publicada no antigo suplemento Cultura, do jornal O Estado de $S$. Paulo, p. 4-5, em 11 de agosto de 1990.

Professor do Departamento de Filosofia da FFLCH-USP 
RIBEIRO, Renato Janine. O intelectual e seu outro: Foucault e Sartre. Tempo Social; Rev. Sociol. USP, S. Paulo, 7(1-2): 163-173, outubro de 1995.

Evidentemente, seria tolo reduzir a obra de Foucault a uma contestação a Sartre. O confronto decisivo entre ambos se situa precisamente na questão do humanismo, na do engajamento, na da consciência política.

2 Inédito no Brasil.

${ }^{3}$ Estas cartas, em tradução minha, apareceram no suplemento Mais!, da Folha de S. Paulo, em 14 de agosto de 1994. antidemocrático no comunismo. Mas, antes disso, Sartre - enquanto trocava com Merleau-Ponty as cartas que marcaram a ruptura, por razões precisamente políticas, da amizade que tinham - ia editando nos Temps Modernes o longo artigo Os comunistas e a paz (1952-1954) ${ }^{2}$, que mostrava um simpatizante do PC, porém que lhe fazia reservas, e também as sofria. Para citá-lo: os comunistas "me acusavam de ter espionado a Resistência em favor da burguesia fascista...".

O fundamental, contudo, está numa tese de Os comunistas e a paz: Sartre conclui que a única via política para a esquerda passa pela aliança com o PC. Com todos os seus defeitos, o PC representa a classe operária: ele é a organização política que assumem os movimentos sociais. Não há alternativa viável a ele. A única saída para quem pretende um movimento de esquerda democrático consiste em dialogar com o PC: em recusar a exclusão a que é submetido pelos assim-chamados socialistas, em evitar assim que ele assuma por conta própria esse isolamento ao qual foi forçado e se encerre em políticas cada vez mais radicais, que, por isso mesmo, só reforçam sua condição de pária da política. Digamos que esta era a posição mais oposta que se podia ter ao que fazia a SFIO, o velho partido socialista, que firmara com o centrodireita um acordo tácito pelo qual se esterilizava a extrema-esquerda. Sartre quer, literalmente, devolver-lhe a vida, a fecundidade; ora, isso significa que, entendendo o stalinismo como reação defensiva, quanto maior for o diálogo aberto com os comunistas, mais condições terão eles de se abrir e de se democratizar. O filósofo assim reconhece uma razão no isolamento praticado pelo PC mediante a estratégia da "guerra de classes", mas isto não significa que ele lhe dê razão: há que retirar o anátema, para que o Partido se integre na sociedade e lhe traga a vitalidade operária.

Esse é o quadro que reduz a estranheza que reponta à leitura, hoje, de certos textos duros, como por exemplo as cartas que Sartre mandou a Merleau-Ponty ao condenar a reticência deste seu amigo em face da política comunista e/ou soviética ${ }^{3}$ : correspondência esta que, lida hoje, causa razoável antipatia do leitor pelo filósofo do engajamento. Convém então lembrar que, na política francesa no tempo da guerra fria, os gabinetes podiam ser efêmeros, mas sua rápida alternância se dava quase sempre em torno de um consenso centro-direita/centro-esquerda, o qual excluía parcialmente do governo a direita e completamente do poder a esquerda (os comunistas). Um acordo tácito ou explícito estipulava que nenhum governo socialista considerasse, na maioria de votos de que necessitava no Parlamento, os comunistas, que eram assim literalmente nadificados. Um eleitor de esquerda assim saberia que, para evitar um governo de direita, não adiantava votar no PCF esperando que este desse um apoio crítico a um gabinete socialista: pela simples razão que tal gabinete não consideraria, nos votos de que precisava, os dos comunistas. A extrema-esquerda era, assim, tornada inexistente, ao menos no Parlamento. Ora, esses governos de centro-esquerda ou centro-direita, para conservar as colônias da Ásia e África, travaram as guerras da Indochina e da 
Argélia, massacrando centenas de milhares de asiáticos e árabes. Foi nesse contexto de guerras coloniais genocidas, de crescente subordinação da França ao aliado norte-americano e de exclusão ou mesmo repressão aos movimentos operários, que Sartre formulou sua estratégia de relação preferencial com o PCF. "Não podemos tirar as esperanças de Billancourt": essa sua célebre frase, aludindo ao subúrbio parisiense da indústria automobilística, contém todo um programa.

Tendo de escolher entre dois males - o comunismo stalinista e o capitalismo imperialista - qual deles preferir? Desde 1948 e a estréia de sua peça As mãos sujas, conhecia-se a resposta de sua personagem, o líder comunista Hoederer. "É preciso sujar as mãos", dizia ele, para horror do intelectual Hugo, também comunista, mas que da doutrina revolucionária só aceitava os princípios, não a eficácia. Temos aqui a nítida contraposição, para empregar termos weberianos, de uma moral da convicção, a de Hugo, a uma da responsabilidade, a do líder partidário. Numa análise clássica desta peça (Sartre par lui-même, 1955), Francis Jeanson elogia Hoederer e mostra, na personagem do intelectual pequeno-burguês - cheio de dúvidas, de pouca potência sexual o desdém de Sartre por uma posição dúbia e vacilante. Não concordo, porém, com Jeanson, que, envolvido em várias causas políticas (será, pouco depois, o articulador do apoio em território metropolitano às ações até mesmo terroristas da Frente de Libertação Nacional argelina $)^{4}$, não tinha dúvidas sobre o sentido e a necessidade da luta política. Sartre não está inteiramente do lado de Hoederer. Embora despreze Hugo, confere-lhe pelo menos um traço básico de sua filosofia: o intelectual não abre mão da responsabilidade pelo ato que cometeu - o assassínio de Hoederer -, ainda que "absurdo" (porque, primeiro, os dirigentes comunistas que o encomendaram depois vieram a mudar de idéia, ao saberem que as idéias do morto coincidiam com as de Moscou; segundo, porque Hugo se viu convencido, por Hoederer, da justeza de suas posições, e somente o matou ao surpreendê-lo com sua mulher). Para usar os termos de Sartre, o homem é o que faz, a existência precede a essência: Hugo é o matador de Hoederer. Os motivos terão sido maus, não importa. Ele não pode renegar o que fez.

De toda forma, Hoederer vai ter, aos olhos de Sartre, cada vez mais razão, à medida que a guerra fria se prolonga e com ela as guerras quentes nos territórios coloniais. Se queremos agir, temos de tomar partido, "sujar as mãos", e não só no sangue, que é nobre, mas também "na merda" - nas alianças sujas, na mentira. Na verdade, há uma velha tradição terrorista dos intelectuais, que apreciam - desde os niilistas do século XIX, pelo menos - os atentados, a morte sacrificial do outro, até mesmo o sacrifício de si, o suicídio sagrado do revolucionário; mas uma palavra é a chave, neste contexto: é que se trata de ações nobres, validadas pela entrega de si, até mesmo - é o que insinua esse inteligente Hoederer - armadas por um ódio a si mesmo. Ora, Hoederer, antes de mais nada, ama a vida em toda a sua densidade e mesmo vulgaridade: corpos, comida, prazeres. A revolução não rompe com o homem que existe,
${ }^{4}$ Uma última grande aparição de Jeanson ocorre no filme A chinesa, de Godard, quando ele explica a uma estudante maoísta a diferença entre a violência revolucionária que se apóia nas massas (a que a FLN argelina praticara) e uma violência sem ligação com o povo. 
para instituir, como quer Hugo, um homem ideal sem nada em comum com o vulgo de nossos dias. Por isso, o enfrentamento de ambos se dá, em boa medida, seguindo o confronto do ideal nobre e da realidade vulgar, de um espírito desvairado e da materialidade elementar. Dizendo de outro modo, esse confronto é a contestação do registro nobre pelo vulgar, de um espiritualismo que se travestiu de esquerdista pelo materialismo que serve de base à própria revolução, enquanto prática e não idéia. A verdade do que passava por nobre está em suas tripas. É assim a pequena moral do intelectual que entra em xeque.

Mesmo assim Sartre, em dois momentos decisivos, afastou-se do PC. O primeiro foi na repressão soviética à revolta húngara de 56 , a primeira grande tentativa de unir democracia e comunismo, antes dos fracassos de Dubcek, na Tchecoslováquia de 1968, e de Gorbatchev, na segunda metade dos anos 80. Sartre tomou então a defesa dos rebeldes contra "o fantasma de Stalin", embora acabasse se reaproximando do PC.

A segunda ruptura, e esta definitiva, se dá em 1968. O PC finalmente se revela um partido burocrático, disposto a sacrificar a chance revolucionária de maio-68 a ganhos salariais e ao reconhecimento, pelo poder gaullista, do poder sindical e partidário dos comunistas (os acordos de Grenelle). Sartre vai então para os gauchistes, a extrema-esquerda, mas preferindo os maoístas.

Por que os maoístas? Talvez Sartre não se tenha afastado do ideal de um PC: um partido forte que organize e represente as massas. Anarquistas e trotskistas criticavam esse modelo - sobretudo os primeiros. Já os maoístas europeus geralmente se propunham a "reconstruir" um PC que se teria debilitado. Não rompiam com o molde leninista. Sua grande contribuição eram novas reflexões sobre os intelectuais, de quem suspeitavam, e muito, graças, sobretudo, à Revolução Cultural chinesa e ao assim-chamado pensamento de Mao Tse-tung.

Aqui temos dois pontos essenciais no pensamento político de Sartre. Sua reflexão foi balizada pela presença, no horizonte, de um PC forte com o qual negociar, e governada, de dentro, por forte suspeita que sentia quanto aos intelectuais (inclusive a si mesmo), que facilmente viravam "ratos gosmentos". Esse horizonte deixou de existir, de fato, desde 1990, e de direito desde 1968, quando o PCF se revelou um partido mais interessado em sua própria estrutura de poder do que em transformar o mundo. Já os intelectuais, mesmo de esquerda, mudaram de posição quanto à classe operária, reduzindo a culpa que sentiam e passando a defender mais as liberdades "formais" ou "burguesas". O trabalhador hoje não tem mais por modelo o operário das indústrias pesadas ou de transformação. Mas o principal é que, sem o PC e sem a culpa, o intelectual de esquerda deixa de ter Sartre como ferramenta que lhe explique a política.

Somente para encerrar esta parte, enfatizemos, a par dessa amizade tensa de Sartre com os PCs (que o faz, no rescaldo de 68, optar pelos maoístas, 
os quais pretendem uma espécie de reconstrução dos partidos somada a uma crítica devastadora aos intelectuais), a importância que tinha em seu pensamento a culpa do homem de letras. Este, mesmo militante, aparece como o modelo por excelência do pequeno burguês. As dúvidas, que constituem talvez o cerne da atividade intelectual, passam assim a ser lidas como vacilação. Todo um modo de ser, ou melhor, de produzir - que é o da atividade de pensar - vê-se assim traduzido em termos de militância política, e nesse contexto é condenado. Talvez um dos traços essenciais da nova política dos intelectuais, desta que acaba tendo em Foucault e em 1968 (mas num 68 diferente do que Sartre entendeu) seus pontos de reparo, seja, exatamente, o fato de que essa culpa se esvazia ou, pelo menos, se reduz significativamente.

Será espantoso que o papel que foi de Sartre, nas duas décadas que vão do fim da II Guerra Mundial até o fim da guerra da Argélia, fosse assumido por Foucault - com as mudanças que veremos - após maio de 68? Refirome ao papel de pensador político de referência, por vezes na moda, eventualmente quase um guru. Os dois filósofos começaram se defrontando com hostilidade explícita quando Foucault, "estruturalista" (como então se dizia), publicou As palavras e as coisas, em 1966. Nesse pensamento que submete a vasta pluralidade de pensamentos, sensibilidades e ações de toda uma época (por exemplo, dos séculos XVII e XVIII) a uma única rede conceitual, a uma episteme, Sartre via uma ameaça de tecnocrata àquilo que para ele sempre constituiu o maior dos valores: a liberdade humana. Neste sentido se deve ler, por exemplo, sua entrevista à revista $L^{\prime} A r c$, por essa época, em que condena os procedimentos estruturalistas. Quer dizer - está implícito no que afirma Sartre contra Foucault, naqueles anos - que o que os homens fazem seria apenas murmúrio vão, como o do ator de Macbeth que vem à cena, cumpre sua parte, e se vai? Sartre sempre reservou os direitos da consciência humana, e assim leu tanto a psicanálise quanto o marxismo. O caso é particularmente significativo porque essas duas teorias lançam radical suspeita sobre aquilo de que os homens têm consciência, ao mesmo tempo em que voltam a atenção para o inconsciente (entendendo por ele quer o id, quer as relações de produção). Ora, o que fez Sartre em ambos os casos foi reduzir o papel do inconsciente, para valorizar a liberdade que, conhecendo-o, aclarando-o, ilumina-se melhor para suas escolhas. Já Foucault o que fez foi acentuar esse primado do inconsciente, entendido como aquilo que sequer pode vir à consciência, a ponto de até pôr em xeque a questão tradicional da liberdade.

Com isso todo o mundo do engajamento político, à maneira sartriana, é posto em xeque. Se a consciência que temos do que sucede é menor do que se supunha, que importância tem discutir as questões políticas? Que primado pode ter o intelectual sobre o homem da mera ação prática, se o desconhecimento que os une é maior do que a eventual vantagem do primeiro sobre o segundo? Sartre, se nunca reivindicou para o intelectual uma superioridade política sobre os demais homens, na prática assumiu porém um papel algo parecido, de consciência moral pública sobre o político. Ora, é esse papel 
mesmo que Foucault contesta, retirando, aliás, todas as consequências dessa contestação. E esta se mostra ainda mais forte, se lembrarmos que para Sartre a questão se joga nas palavras; que deu esse título a sua autobiografia, de 1962; e que para Foucault, seu biógrafo Didier Eribon o repetirá várias vezes, escrever surgiu por acaso e (pelo menos ele o dizia - podia ser coqueteria do próprio Foucault) poderia não ter surgido.

Foucault, pelo que nos revela Eribon, é tudo, menos um personagem com projeto: sua integridade, sua coesão vão-se formando a partir de facetas que antes se contradiziam e cujo surgimento parece, às vezes, fortuito. Ele quis, de início, fazer carreira diplomática, a exemplo de muitos intelectuais que trabalham nos serviços culturais e nas Alianças Francesas; em Uppsala, na Suécia, deu conferências, mais de literatura que de filosofia. Perto de morrer, quis fazer-se jornalista, e nessas condições foi para o Irã, presenciar a agonia do regime do Xá. Não foram meras fantasias, no começo e no fim de sua vida adulta; dessas duas profissões ficaram resultados sólidos. Mostravam ambas um gosto acentuado pela dimensão pública, pela fala que reverbera para fora do meio apenas acadêmico. Onde ele melhor realizou esse gosto foi, está claro, na atividade de professor e escritor. Mas como satisfazer essa dimensão pública, para um intelectual, sem se tornar consciência sartriana?

Como professor no Collège de France, Foucault impressionava. Era um ator estupendo, sabe-o quem o viu alguma vez falar: atrás de uma pequena lâmpada, que lhe iluminava apenas parte do rosto e do busto, ele falava; cada movimento que fizesse - e cuidava para que fossem poucos tinha o efeito multiplicado, pela luz, pela escassez de gestos; preparava os 75 minutos de aula montando uma demonstração fascinante, de poderosa argumentação, mas que alcançava uns cinco ou sete momentos culminantes, frases que sintetizavam o que precedia e constituíam fórmulas que ficavam gravadas - de tal modo que a cada dez minutos ou doze se chegava a um patamar, sempre (ou quase) demolidor de imagens feitas. Como um número cada vez maior de ouvintes levasse gravadores portáteis para registrar suas aulas, ele por coqueteria ou generosidade ou, mais provável, ambas - passou a fazer um rapidíssimo entreato, de um ou dois minutos, na metade da aula, quando contava uma anedota, exemplar das teorias que estava criando; o que, aliás, apressava ainda mais os donos dos gravadores, desesperados por terem, também, esta mediação quase lúdica que se introduzia aos quarenta e cinco minutos de fita.

Esse Foucault, que dominava tão bem o seu público, não se teria tornado um tanto sartriano? Quero apenas dizer (Sartre nunca teve essa maestria na fala, ou esse público regular - era um escritor): depois de tanto criticar o filósofo-porta-voz, Foucault veio a sentir-se bem no papel do pensador que fala e é ouvido. No entanto, os tempos haviam mudado, e na sua atuação política, que começou relativamente tarde, os problemas com que se defrontou foram muito distintos dos que Sartre teorizou.

Antes de mais nada, Foucault mal teve de lidar com a militância, no sentido tradicional, de um partido político consolidado e forte. Ainda havia 
RIBEIRO, Renato Janine. O intelectual e seu outro: Foucault e Sartre. Tempo Social; Rev. Sociol. USP, S. Paulo, 7(1-2): 163-173, outubro de 1995.

militância, é claro, nos grupúsculos de extrema esquerda, e que então parecia ter certa importância (mais ou menos entre 68 e 72 ou 73), mas quem dialogou com ela foi Sartre - que, vimos, cessara de falar com o Partido Comunista. A política em que Foucault acreditava ele teorizou num diálogo com Gilles Deleuze que aparece no número 49 de $L^{\prime} \operatorname{Arc}^{5}$ (1972): afirma ele que o poder do policial é da mesma natureza que o do primeiro-ministro - ou seja, ambos, embora sua esfera de atuação seja diferente, têm em comum o fato de impedirem as pessoas de fazerem o que querem, e de obrigá-las a fazer o que não querem. O "Circulez!" do policial passa a ser visto como revelador da essência do poder, tanto quanto as leis e decretos governamentais; uma língua ferina poderia até criticar Foucault por de algum modo reduzir a complexidade do poder a esse gesto elementar do policial. De todo modo, mais tarde, à medida que ele desenvolver a idéia de que o poder é produtivo e repudiar explicitamente a tese libertária de que, retirando-se a coerção, cem ou mil flores hão de florir, é claro que tal reducionismo, se um dia ocorreu em seu pensamento, deixará de fazer sentido para ele.

Mas de todo modo, se na sociedade estão semeados estes mil poderezinhos que nos oprimem, como enfrentá-los senão fazendo florescer milhares de ações pontuais? Daí que Foucault defenda a ação local, que a seu modo pode ser exemplar, isto é, difundir novas possibilidades de vida. É a época em que a fábrica de relógios Lip vai à falência, e seus operários entram em conflito com o governo porque querem assumí-la eles mesmos, numa proposta de autogestão que poderia ser ameaçadora para a tese capitalista segundo a qual somente o empresariado assegura a racionalidade necessária à direção dos negócios: se o recorte capital-trabalho deixar de recobrir as divisões racionalidade-obediência, decisão-execução, que será do capitalismo? Ao mesmo tempo, um campo de pastores no Larzac, região do sul da França, é desapropriado pelo exército para servir de campo de tiro e se torna emblema das causas, a um tempo, pacifista, ecologista e camponesa - politizando, ademais, uma camada, a dos trabalhadores do campo, tradicionalmente conservadora. As violências da polícia contra árabes e negros, no final da presidência Pompidou, e a mobilização da opinião pública contra a pena de morte somam-se a este quadro, em que cada uma das lutas descritas, em vez de preparar a "luta final" que substituirá o capitalismo pelo socialismo, tem riquezas próprias, deve ser respeitada em si mesma e não subordinada a uma racionalidade superior e externa, à do Partido, da qual se sabe, só, que não deu certo ${ }^{6}$.

Eé o que mostram dois grandes exemplos de atuação de Foucault naqueles anos. Um foi o Grupo de Informação sobre as Prisões (GIP), que ajudou a fundar, em 1970. Outro foi o livro sobre Pierre Rivière.

O GIP foi algo inédito, pelo menos na França (a Anistia Internacional tinha, no mundo afora, uma atuação que recobria alguns de seus aspectos e ultrapassava outros, mas sem a doutrinação francesa ${ }^{7}$. Não defendia os presos políticos em particular, mas - sobretudo - os de direito comum. Ora, os intelectuais, franceses ao menos, podiam se interessar pelos presos, mas só
5 Também publicada, como Os intelectuais e o poder. Conversa entre Michel Foucault e Gilles Deleuze (1984a).

${ }^{6}$ É inevitável uma referência à Sexpol de Wilhelm Reich: o cientista da sexualidade, militando no PC alemão, iniciava alguns anos antes da tomada do poder pelo nazismo um empreendimento voltado especificamente para os jovens, a fim de enfrentar sua "miséria sexual" através de uma educação libertária e esclarecedora, bem como do incentivo a locais onde pudessem se encontrar para ter uma vida sexual limpa e prazerosa. O Partido apreciou a iniciativa enquanto ela ampliava os quadros de seus membros, mas bloqueou-a depois, devido ao conservantismo de outros militantes. Este é um paradigma da forma pela qual uma luta dita "local" ou "específica" (e no entanto de enorme am-plidão) se vê congelada pela subordinação à luta final. Evidentemente, seria absurdo imaginar que o legado imediato de maio de 68 fosse a contestação deste modelo. Os maoístas, já vimos, mantinham o modelo do PC, desde que "reconstruído" e que agravada sua desconfiança dos intelectuais. Entre os trotskistas, um slogan que se repetia proclamava, pa-ra qualquer problema, "uma única solução, a revolução". A grande organização 
RIBEIRO, Renato Janine. O intelectual e seu outro: Foucault e Sartre. Tempo Social; Rev. Sociol. USP, S. Paulo, 7(1-2): 163-173, outubro de 1995.

trotskista chamava-se Liga Comunista. Somente a médio ou longo prazo é que se firma a imagem de 68 como uma crítica, não a um PC traidor de seu próprio ideal, mas à proposta mesma de um PC vanguarda das massas. Digamos, sucintamente, que Sartre endossa mais a primeira crítica, e Foucault a segunda. 7 Com efeito, a Anistia Internacional defende a libertação de todos os presos de opinião, a supressão da pena de morte, condições decentes de julgamento para todos os réus e de cumprimento da pena para todos os condenados. Seu roteiro é portanto distinto do do GIP, embora se encontrem em vários pontos.

${ }^{8}$ Recorde-se que por essa época faz sucesso na França a trilogia de filmes Français, si vous saviez, sobre a era gaullista, dos quais um - Je vous ai compris - mostra a tomada do poder por de Gaulle em 1958. "Eu vos compreendi" é a frase-chave do discurso que o general profere naquele ano em Argel, perante os colonos franceses cuja revolta, ante a possibilidade de independência da Argélia, fora o fator que o levara ao poder. Ora, quatro anos depois o presidente de Gaulle firmava os acordos que reconheciam uma Argélia independente. Eu vos compreendi passa então a ser o motto de como idéias e sentimentos são anexados, traduzidos e para conferir sentido e destinação a sua luta; pois foi justamente isso o que Foucault se proibiu. Os cadernos do GIP traziam depoimentos, davam a palavra a quem não a tinha; essencial, aí, era romper com o padrão de ser "voz de quem não tem voz", que apareceu em parte da pedagogia progressista de matriz católica, ou de quem traduz, decifra, totaliza, interpreta melhor mesmo do que o sujeito falante o que este deseja (ou o que este tem de desejar) ${ }^{8}$.

O livro sobre Pierre Rivière segue a mesma inspiração. É uma obra menor de Foucault, e por algum tempo se viu um tanto superestimada, até favorecendo, como se fossem foucaultianos, textos de qualidade menor, meras coletas de arquivos sem análise. Nele, Foucault não quis interpretar o que dizia esse matricida do século XIX, que a normalidade considerou louco; em vez de analisá-lo, os autores do livro redigiram textos complementares ao do próprio Rivière. Daí, quando o lemos, uma certa frustração. Mas proposital, porque produzindo-a Foucault rompia exatamente com o modelo que podemos, com alguma perfídia e exagero (mas apenas alguma), denominar sartriano.

Sartre, por essa época, compreendia Flaubert, como antes havia compreendido Baudelaire; é isso o que Foucault se recusava a fazer. Estranhamente, Foucault, que acreditava no inconsciente, não queria desmantelar a consciência que alguém - até mesmo um preso, personagem usualmente desdenhada - tinha de si e de sua situação (e com o tempo ele veio a pensar que essa consciência era bastante justa, e merecia respeito não só ético, mas também no plano do conhecimento), enquanto Sartre, para quem as escolhas sempre foram algo prioritário, admitia ser a consciência alheia.

Na verdade, porém, as duas posições são coerentes com as idéias de seus defensores. A importância da consciência e da liberdade, em Sartre, permitia que ele discutisse a obra ou a vida alheia sem se situar num plano superior ao do outro: uma certa comunidade de mundo une a todos nós. Dizer, aliás, que Sartre pretendesse ser a consciência alheia é fazer-lhe uma crítica externa a suas convicções - uma crítica foucaultiana - e vazada em termos que não são seus. Pois o que a importância do inconsciente ensinou a Foucault foi humildade intelectual, negando-lhe e a qualquer outro credenciais para proferir um discurso definitivo ou mesmo superior, estabelecendo uma autonomia irredutível de cada discurso ou prática a qualquer outro. Trata-se da recusa da recuperação, a que aludimos antes ${ }^{9}$. O risco disso, sabemos (e foi apontado), está em cortar de vez o diálogo, em negar entre os homens a possibilidade de se constituir uma comunidade: mas Foucault se importava menos com os riscos que seu pensamento causasse para os pensadores da ordem social, do que com a contribuição que pudesse dar a novas falas e ações.

E, sobre o novo, uma palavra. Terá sido este um ponto decisivo na atuação de Foucault, não só porque contribuiu extraordinariamente para renovar as ciências humanas e a própria filosofia, mas também porque sua própria démarche destacava o novo, o inédito: eram deste teor as frases de maior efeito com que, dissemos, pontuava suas aulas no Collège de France, e era também deste modo que construía suas obras, quer em suas teses principais, 
RIBEIRO, Renato Janine. O intelectual e seu outro: Foucault e Sartre. Tempo Social; Rev. Sociol. USP, S. Paulo, 7(1-2): 163-173, outubro de 1995.

quer na simples composição, surpreendente, de sua escrita ${ }^{10}$. De teses surpreendentes, citemos pelo menos duas: a conclusão de As palavras e as coisas, segundo a qual é consolador imaginar que a figura do homem (enquanto objeto dotado de inteligibilidade própria - mas esta ressalva não fica evidente) desaparecerá em breve do horizonte de nosso saber - o que, sem a ressalva entre parênteses, parece tudo, menos consolador; e a tese que norteia $A$ vontade de saber, segundo a qual o que distingue a sexualidade moderna ocidental é menos a repressão (segundo o lugar-comum que por ela responsabiliza a rainha Vitória, e o qual o próprio Foucault antes havia exposto, em aulas) do que uma hybris de conhecimento: mais, portanto, lançando luzes do que um véu sobre as coisas do sexo. De frases de espantoso efeito, baste recordar, nos mesmos livros, a enciclopédia chinesa citada no início de As palavras e as coisas, e o comentário, em A vontade de saber, segundo o qual nossa cultura é a única que tem prepostos pagos para ouvir confissões: como se fosse tal o descompasso entre o desejo de falar e a disposição a ouvir, que se tornasse necessário adequar a oferta à demanda.

Terá sido este destaque dado ao novo, esta sofreguidão com que Foucault e seus leitores pactuavam na busca do que fosse diferente, um dos traços decisivos do clima intelectual dos anos 70. Suponho assim que seu impacto sobre a chamada "nova história" devesse muito ao desejo de romper imagens feitas e promover pesquisas cujo efeito fosse, ao pé da letra, surpreendente. Mas é claro que as próprias surpresas se esgotam, e que por vezes engendram uma nova ortodoxia; isso terá ocorrido, penso, em boa parte da nova história ${ }^{11}$; mas, por esse efeito, Foucault não é responsável.

Assim foi que os caminhos dos dois pensadores mais impressionantes do último meio século francês vieram a se cruzar: Foucault, tornandose personagem público, sempre tentou negar (o quanto lhe permitiram os media, a que tinha fácil acesso) o papel de guru; Sartre, cortando a interlocução preferencial que mantivera com o PCF, tornou-se amigo dos grupúsculos maoístas. Participaram, juntos, de várias manifestações.

Se, até o fim, Sartre parece ter conservado uma certa simpatia pelo comunismo - agora o da versão que se dizia mais autêntica, a maoísta, o que o atraía neste não era a figura do presidente chinês, mas a ênfase nas lutas dos trabalhadores, a combatividade que demonstravam; com isso, seu pensamento se tornou menos globalizante, mais pontual - assim como as ações de que participava, e que eram tão soixante-huitardes quanto as dos filósofos da época, esses jovens que não eram seus discípulos. Nada expressa melhor suas convicções da última fase de vida do que a frase que então imprimiu: Sempre há razão em se revoltar. Esta frase talvez pudesse ser assinada pelo professor Michel Foucault, do Collège de France - que, embora não conferisse o mesmo privilégio às lutas operárias, deu pleno apoio a todas as lutas de "minorias" (árabes, judeus, negros, minorias nacionais, homossexuais, ecologistas, mulheres, presos) com que se deparou.

Mas esse gosto pelas ações pontuais não terá impedido Foucault de traídos ao se incorporarem naquilo que pretende ser uma racionalidade superior. Contra esse empreendimento de "recuperação", valoriza-se uma concepção de cada discurso como irredutível. E pouco importa, no caso, que tenham sido traídos os setores de extrema-direita: o empreendimento de tradução/ traição é visto como dispositivo essencial do poder.

${ }^{9} \mathrm{Na}$ nota imediatamente anterior.

${ }^{10}$ Desenvolvemos este ponto em $O$ discurso diferente (Ribeiro (org.), 1985), artigo que republicamos, modificado, em $A$ última razão dos reis ensaios de filosofia $e$ de política (1993).

${ }^{11} \mathrm{Cf}$. meu artigo $O$ risco de uma ortodoxia (1994).

${ }_{12} \mathrm{Na}$ passagem em que afirma que o motivo que o levou a escrever essa obra foi "a única espécie de curiosidade que vale a pena [...]: não aquela que procura assimilar o que convém conhecer, mas a que permite separar-se de si mesmo" (Foucault, 1984b, p. 13). 
pensar globalmente o político? Essa crítica foi feita várias vezes - por exemplo, no debate de encerramento do Colóquio Foucault da USP, em 1985: não seria a ausência de uma teoria do político que o teria levado a erros graves, como a simpatia que expressou pelo aiatolá Khomeini nos artigos para o Corriere della Sera, em 1978-79?

Ora, comecemos negando a gravidade do erro: esses poucos artigos em nada concorreram para a instituição da República Islâmica no Irã; se Foucault errou, sua teoria pelo menos não porta nenhuma responsabilidade pelos males do mundo. O liberalismo, a social-democracia, o marxismo não podem dizer a mesma coisa.

O que surpreende, porém, nos artigos em questão, é o comedimento de Foucault. O que diz ele? Primeiro, que uma vitória de Khomeini mudaria por completo os dados no Oriente Médio. Isto se confirmou. Depois, que via a política trilhar novos caminhos, esquecidos do Ocidente: "Uma espiritualidade política". Também acertou. O problema então é apenas um: Foucault, com sua simpatia por tudo o que era dissidente em face dos discursos/práticas ocidentais, deu crédito (e talvez não muito) a um movimento que acabou exterminando tudo o que fosse dissidência.

Aí está a questão, que hoje facilita os ataques a Foucault por parte daqueles que voltam a exaltar o Ocidente e o liberalismo que ele e os pensadores franceses dos anos 70 desmontaram. Mas quem leu esse pensamento sério e apaixonante, profundo e ferino, não pode contentar-se com uma tal volta do pêndulo, que reconstitui a razão, a democracia, o consumo como valores definitivos. De Foucault lembremos a prudência intelectual que tão bem se lê na sua descrença das palavras, em particular das grandiosas, "universais". No Irã ele viveu uma experiência, que poderia, tivesse mais sorte, ser a dos seus nhambiquaras (porque, se quisermos um dia perguntar onde Lévi-Strauss viu cair sobre a cabeça sua "maçã de Newton", aquilo que o fez pensar, terá sido no Mato Grosso: a lição de escrita, relatada nos Tristes trópicos): como um etnólogo, como um aventureiro, ele tentou viver os sinais de mudança - como poderia ter sido em Lip ou no Larzac. Frustrou-se, errou mesmo. Seus índios estavam em Paris, ou na Califórnia, ou em toda a parte; sem dúvida, eram menos límpidos que os de Lévi-Strauss, sua selvageria não era boa. Mas esta curiosidade, que ele elogiou no início do Uso dos prazeres ${ }^{12}$, esse cuidado intelectual, fizeram-no recusar o que fosse sistema acabado, o que passasse por óbvio. Sabemos de pensadores que se afastam dos poderes constituídos; estão entre os melhores; Foucault, contudo, foi além: afastou-se até das identidades constituídas. Por isso, até seus equívocos aclaram. E talvez pudéssemos concluir com uma passagem de Nietzsche, na epígrafe da Gaia ciência:

E zombei de todo mestre

Que não zombou de si mesmo. 
RIBEIRO, Renato Janine. O intelectual e seu outro: Foucault e Sartre. Tempo Social; Rev. Sociol. USP, S. Paulo, 7(1-2): 163-173, outubro de 1995.

RIBEIRO, Renato Fanine. The intellect and his other: Foucault and Sartre. Tempo Social; Rev. Sociol. USP, S. Paulo, 7(1-2): 163-173, october 1995.

ABSTRACT: Foucault reflected upon the role of the intellect by contesting Sartre and the pressupositions of the engagement, especially the ones associated to the philosophy of conscience and humanism. After 1968, however, when the political bases of sartrism crumbled - particularly the proximity of the Communist Party -, Sartre could make common force with Foucault at the same time the latter assumed, willing of not, roles he had always refused, as the one of being a public voice.

\section{REFERÊNCIAS BIBLIOGRÁFICAS}

Foucault, Michel. (1984a) Os intelectuais e o poder. Conversa entre Michel Foucault e Gilles Deleuze. In: edição. Rio de Janeiro, Graal. p. 69-78. . Microfísica do poder. $4^{\mathrm{a}}$ . (1984b) História da sexualidade II - O uso dos prazeres. Rio de Janeiro, Graal.

RIBEIRo, Renato Janine. (1985) O discurso diferente. In: . (org.) $R e-$ cordar Foucault. São Paulo, Brasiliense.

Foucault, Sartre, intellect, engagement, politics. . (1993) A última razão dos reis - ensaios de filosofia e de política. São Paulo, Companhia das Letras. . (1994) O risco de uma ortodoxia. Revista USP, São Paulo, nº 23: 613.

Sartre, J. P. (s/d) O fantasma de Stalin, Rio de Janeiro, Paz e Terra. 
RIBEIRO, Renato Janine. O intelectual e seu outro: Foucault e Sartre. Tempo Social; Rev. Sociol. USP, S. Paulo, 7(1-2): 163-173, outubro de 1995. 